\title{
INVESTIGATION OF THE PROCESSES CONTROLLING THE FLAME GENERATION OF REFRACTORY MATERIALS
}

\author{
DOE/ER/45356--7 \\ Progress Report \\ for the Period \\ DE92 008189 \\ July 1, 1991 - June 30, 1992
}

Professor Joseph L. Katz

Principal Investigator

The Johns Hopkins University

Baltimore, MD 21218

Report Prepared: January 1992

Prepared for

Office of Basic Energy Sciences

U.S. Department of Energy

Agreement NO. DE-FG02-88ER45356 


\section{NOIIC\&}

This report was prepared as an account of work sponsored by the Unlted States Government. Nelther the United States nor the Department of Energy, nor any of their employees, nor any of their contractors, subcontractors, or their employees, makes any warranty, express or implied, or assumes any legal liabllity or responsiblity for the accuracy, completeness, or usefulness of any information, apparatus, product or process disclosed or represents that its use would not infinge privately-owned rights. 
The processes involved in the formation of mixed oxides powders were studied using the counterflow diffusion flame burner. Powders of different morphologies were obtained by varying the flame conditions (temperature, residence time) and the concentration ratio of the oxides precursors. In-situ particle size and numberu density were determined using dynamic light scattering and $90^{\circ}$ light scattering. A thermophoretic sampling method and a larger scale powder collection device also was used to collect particles, and their size and morphology examined using transmission electron microscopy, $\mathrm{X}$-ray diffraction and surface area measurement by gas absorption (BET). Our emphasis has been on $\mathrm{TiO}_{2}-\mathrm{SiO}_{2}, \mathrm{SiO}_{2}-\mathrm{GeO}_{2}$ and $\mathrm{Al}_{2} \mathrm{O}_{3}-\mathrm{TiO}_{2}$. The powders had a core-mantle-like (one oxide coated by the other) at low elevations in the burner and uniform mixture at higher elevations. They form chain-like structures in a low temperature flame and spherical particles in a higher temperature flame. Nanometer sized homogeneous particles of Aluminum Titanate could be obtained using $\mathrm{Al}\left(\mathrm{CH}_{3}\right)_{3}$ and $\mathrm{TiCi}_{4}$ as precursors both in a hydrogen fueled and a methane fueled counterflow diffusion flame burner, as well as in a hydrogen fueled parallel-flow diffusion flame burner.

A number of refractory materials are produced annually as fine particles by combustion synthesis of appropriate precursors. However, the physical properties of the materials are strongly dependent on morphology, size, and shape of the particles. The goal of this research is to understand why and how the process variables (flame temperature, precursor concentration ratio, residence time, ...) influence the morphology of particles. This year, we have focused our attention on the formation of mixed oxides powders using a counterflow diffusion flame burner. The morphology, crystalline phase, size, and number density of the particles were determined using Transmission Electron Microscopy, X-Ray diffraction, dynamic light scattering and $90^{\circ}$ light scattering.

During the past year, we have studied three mixed oxides powders : $\mathrm{TiO}_{2}-\mathrm{SiO}_{2}, \mathrm{SiO}_{2} \cdot \mathrm{JeO}_{2}$ and $\mathrm{Al}_{2} \mathrm{O}_{3}-\mathrm{TiO}_{2}$. Reports describing these studies and their analysis have been submitted for publication in the Journal of Materials Research (see attached preprints). We found that the morphology of mixed oxide particles is strongly dependent on the precursor concentration ratio, the flame temperature and the precursors involved. Depending upon the oxides involved, their nucleation is either homogeneous (one oxide nucleates independently of the other) or heterogeneous (one oxide nucleates on the surface of the other). If the flame 
temperature is chosen such that the two oxides involved do not nucleate at the same elevation in the burner, the oxide which first nucleates is partially covered by the second oxide. At elevations in the burner abny that where the oxides condense a core-mantle structure is observed. The core is mainly composed of the oxide which first nucleates and the mantle of the second oxide. The thickness of the mantle can be controlled by varying the precursor concentration ratio. At even higher elevations (thus, at even higher temperatures) the core and the mantle mix to form a homogeneous mixture. However, if the temperature of the flame is such that both oxides nucleate at the same elevation, a core-mantle structure is not observed and the particles formed are then a homogeneous mixture of the two oxides. The flame temperature also influences the shape of the particles: in a low temperature flame the particles are mainly chain-like structures, whereas in a higher temperature flame they are spherical particles.

Aluminum Titanate-based ceramics $\left(\mathrm{Al}_{2} \mathrm{TiO}_{5}\right)$ have received much attention because of their high strength and their low thermal expansion coefficient. In the preprints there is only an initial report on aluminum titanate. In the three months since they were written, our study of aluminum titanate has been significantly extended. Particle morphology depended on precursor concentration ratio and flame temperature in a way very similar to that observed for the other mixed oxides powders. Nanometer sized homogeneous particles of Aluminum Titanate were obtained using $\mathrm{Al}\left(\mathrm{CH}_{3}\right)_{3}$ and $\mathrm{TiCl}_{4}$ as precursors. Using a low temperature flame, particles showing a core-mantle structure were observed at low elevations in the burner $\left(\mathrm{Al}_{2} \mathrm{O}_{3}\right.$ core and $\mathrm{TiO}_{2}$ mantle). The thickness of the mantle depended on precursor concentration ratio. At high elevations, chain-like particles of aluminum titanate were obtained. Using a high temperature flame, the core-mantle structure is not observed at low elevations. Instead chain-like structure of a homogeneous mixture of $\mathrm{Al}_{2} \mathrm{O}_{3}$ and $\mathrm{TiO}_{2}$ particles is found. At high elevation, they fused into spherical particles of Aluminum Titanate.

The hydrogen fueled counterflow diffusion flame burner is a very suitable tool for a study of the formation process of refractory compounds such as mixed oxides particles. It allows independent control of the experimental variables (i.e., temperature, concentrations, residence time) and their in-situ measurements (using light scattering and spectroscopy techniques). 
However, it is not as appropriate for large scale powder production. We investigated whether the particles produced by this burner could be produced using more "industrially" appropriate conditions. Using methane as fuel instead of hydrogen is of industrial interest because of its lower cost, so the formation of $\mathrm{Al}_{2} \mathrm{O}_{3}-\mathrm{TiO}_{2}$ mixed oxide powders using methane was studied. Despite the lower burning velocity, the particles obtained were similar, both in size and shape (chain-like structure and spherical particles) to those obtained using a hydrogen flame. X-Ray diffraction analysis showed that Aluminum Titanate was produced. The role of burner type was investigated by studying $\mathrm{Al}_{2} \mathrm{O}_{3}-\mathrm{TiO}_{2}$ mixed oxide powder formation using a parallel-flow diffusion flame burner, a type of burner more suitable for mass production. It consists of two brass walls, divided into four ports by three Invar plates. The inner two ports are fed with the fuel $\left(\mathrm{H}_{2}+\mathrm{Ar}+\right.$ precursors $)$ and the oxidizer $\left(\mathrm{O}_{2}+\mathrm{Ar}\right)$, whereas the outer ports are fed with pure argon. The $\mathrm{X}$-ray analysis of the powders showed that aluminum titanate is produced using this burner.

Some operational improvements also were made during the past year. We replaced the upper section of the counterflow diffusion flame burner with one constructed completely of stainless steel, thus minimizing serious corrosion difficulties. For powder analysis techniques such as $\mathrm{X}$-Ray diffraction or surface area measurements by gas adsorption (BET) to be used a significant among of powder is required more than could be collected thermophoretically. Thus, a new powder collection device was developed, consisting of two thin stainless strips located on each sides of the burner. When an electric field is applied between the two strips, powders are collected directly onto their surfaces. The placement of the strips in the burner can be adjusted to collect particles at different elevations in the burner. Preliminary studies by nitrogen adsorption (BET method) showed that powders with surface areas ranging from 50 to $150 \mathrm{~m}^{2} / \mathrm{g}$ were obtained, depending on the flame temperature, suggesting that by choosing appropriate flame conditions one indeed can produce powders of sufficiently large surface area to be suitable for use as catalysts.

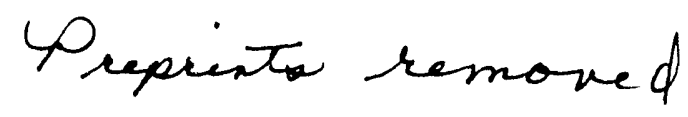



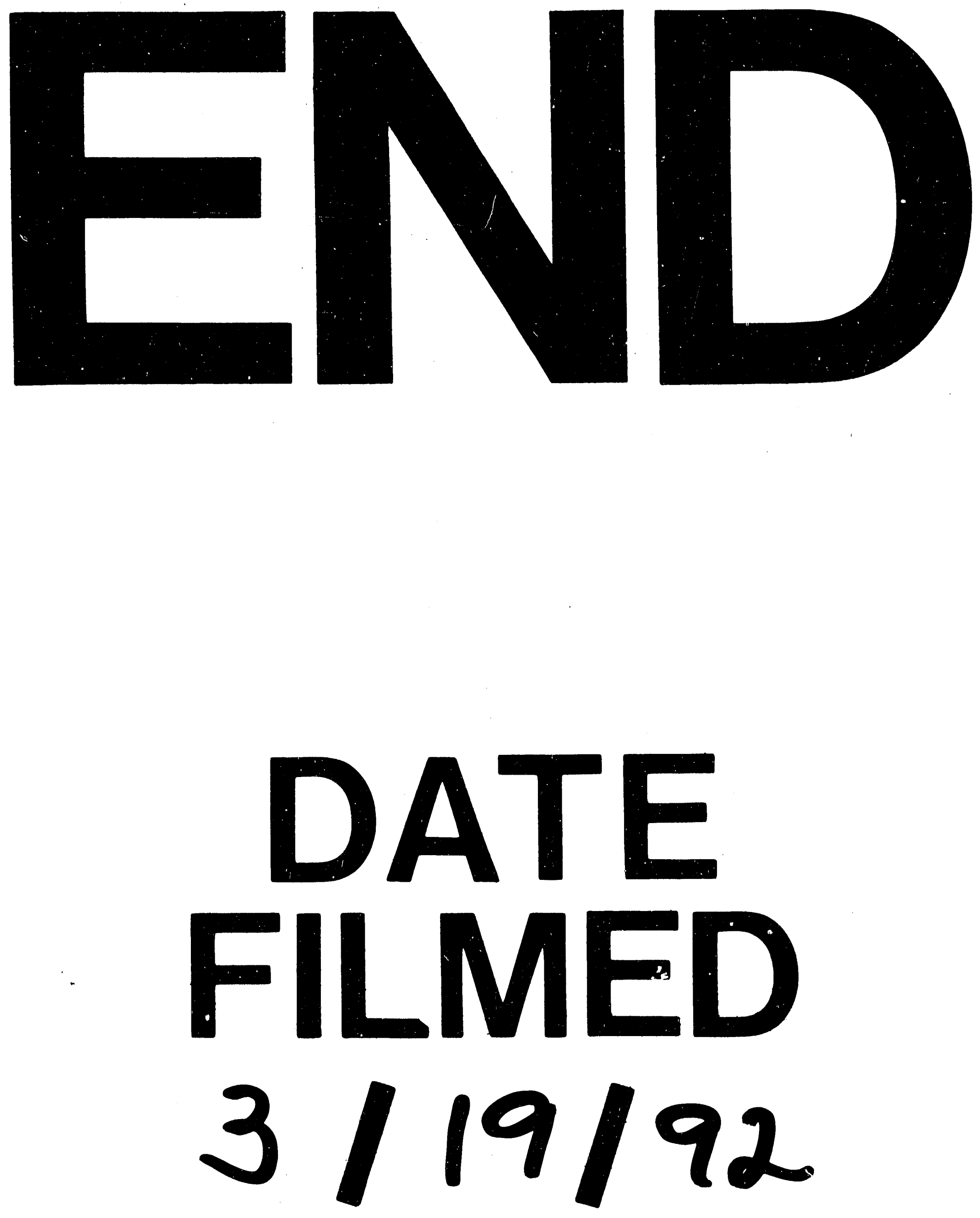

I 
